Research Article

\title{
An Experimental Study Examining the Size Effect on the Compressive Dynamic Performance of Nuclear Power Containment Concrete
}

\author{
Furong Li $\mathbb{D}^{1},{ }^{1,2}$ Guoxing Chen $\mathbb{D}^{\mathrm{D}},{ }^{1}$ and Hui Long ${ }^{3}$ \\ ${ }^{1}$ Institute of Geotechnical Engineering, Nanjing Tech University, Nanjing, Jiangsu 210009, China \\ ${ }^{2}$ College of Civil Engineering, Yancheng Institute of Technology, Yancheng, Jiangsu 224051, China \\ ${ }^{3}$ College of Civil Engineering, University of South China, Hengyang, Hunan 421001, China
}

Correspondence should be addressed to Guoxing Chen; gxchen@njtech.edu.cn

Received 16 January 2020; Revised 31 March 2020; Accepted 10 April 2020; Published 6 May 2020

Academic Editor: Antonio Caggiano

Copyright (c) 2020 Furong Li et al. This is an open access article distributed under the Creative Commons Attribution License, which permits unrestricted use, distribution, and reproduction in any medium, provided the original work is properly cited.

To study the size effect of nuclear power containment concrete (NPCC) under compressive dynamic performance, the cube concrete specimens with 3 different cube sizes were measured at 10 different loading strain rates using a hydraulic servo, and the failure mode and compressive strength of NPCC were compared and analyzed under different loading conditions. Based on the comparative analysis of experiment results, the following conclusions can be drawn: the effect of loading strain rate has caused NPCC to develop from static strain rate, mainly cement cementitious layer damage and uniform distribution of cracks, to dynamic strain rate, where there are partial coarse aggregate failures and oblique cracks as the main crack distribution. Due to the size effect, the integrity of large-scale NPCC specimen after compression failure is relatively high. With the increase of loading strain rate and decrease of cube size, compressive strength of NPCC is gradually increased, and, with the increase of loading strain rate, the size effect on the mechanical properties of NPCC becomes more significant. Moreover, this paper quantitatively analyzes the influence of the coupling effect of strain rate and size effect on the compressive strength of NPCC, and its mechanism is discussed in depth. The research results are of great significance to the safety of nuclear power concrete containment.

\section{Introduction}

As a critical part of a nuclear power plant, containment structures are built with concrete materials. Hence, the concrete properties directly affect the duration life and safety characteristics of a nuclear power plant. Therefore, researches on NPCC properties are of importance. In the working environment, the containment structure is affected not only by static loads but also by the dynamic effect such as earthquakes, wind loads, and shocks. Thus, comprehensive studies on the dynamic performance of the containment concrete structures are necessary $[1,2]$. In view of the importance of the containment structure, finite element calculation and scale-down model tests are two methods mostly used for structural analysis. More specifically, the scale-down model test is the most intuitive and suitable approach for engineering practices, especially for the study of dynamic performance. However, this method is seriously affected by the size effect. While applying the scale-down model test to examine the nuclear power containment structure, the concrete specimens will be influenced by the coupling of size effect and dynamic performance. In view of this, there is critical research significance in examining the mechanical properties of the containment concrete under complex loading environments $[3,4]$.

The size effect of concrete is caused by its brittleness and quasi-brittleness characteristics; that is, the mechanical properties of concrete change significantly with the change of dimension. Significant research efforts focused on the size effect of ordinary concrete. Cao et al. $[5,6]$ have deduced the size efforts of dynamic modulus by means of random aggregate method. Neville [7] studied the compressive strength 
of concrete specimens with 3 different sizes and reported that small-sized specimens showed a higher compressive strength. Sabins and Mirza [8] analyzed the impact of different curing methods and ages on the size effect of concrete. Su and Fang [9] conducted experimental research on the size effect on compressive strength and tensile strength of concrete. Jin et al. [10-12] developed a series of experimental and numerical studies on the size effect on dynamic compressive strength and tensile strength of concrete. Du et al. [13] studied the size effect of concrete from two aspects of materials and components. The concrete dynamic rate effect is that the obvious change in the mechanical properties of concrete was affected by different loading strain rates. Actually, extensive research studies on this topic were published, which are usually conducted by bearing hydraulic servo, drop-weight test, Hopkinson pressure bar, and so forth. Meanwhile, several studies considered the influence of different environmental factors, loading methods, and mix ratios on the dynamic rate effect of ordinary concrete [14]. For example, $\mathrm{Li}$ et al. $[15,16]$ proposed the constitutive models of the dynamic rate effect of ordinary concrete, and Shiming and Yupu [17] analyzed multiaxis dynamic performances of ordinary concrete. With respect to the researches on NPCC, the strength, deformation, and permeability are usually the most concerned aspects. Compared with ordinary concrete, NPCC should be provided with higher durability, and its technical indicators, mix proportions, and pouring techniques need to strictly follow the standards $[18,19]$. At present, the existing researches on the mechanical properties of NPCC mainly concentrate on analyses from the perspective of multiaxial stress, which is partially consistent with the actual situation. Although some research results regarding the dynamic performance of NPCC have been implemented, the coupling of size effect and dynamic performance on NPCC has not been analyzed and reported thoroughly so far. Therefore, a comprehensive research from this perspective is of great importance for the safety characteristics of nuclear power containment structure [20].

The present study conducts a series of experiments to consider the coupling of size effect and dynamic performance on NPCC by using concrete specimens with 3 different cube sizes and 10 different loading strain rates. A hydraulic servo is used to perform uniaxial compression tests on these concrete specimens in order to understand the failure mode and compressive strength of the concrete under different loading conditions. Then, according to the comparative analysis of failure modes and compressive strengths, the variation patterns of the concrete properties under the coupling of size effect and dynamic performance are analyzed from both qualitative and quantitative perspectives. In the end, the failure mechanism and mechanical performances of NPCC are discussed.

\section{Test Setup and Specimens}

2.1. Specimen Design. The mixture design for NPCC generally follows the standard of "Specification for Mix Proportion Design of Ordinary Concrete” (JGJ55-2011), while strictly complying with the durability and material use requirements. For instance, only Classifly ash is allowed to be added, and the substitution rate is not allowed to exceed $10 \%$; the slump of the concrete mix is within $18 \pm 3 \mathrm{~cm}$; the minimum cement amount is $300 \mathrm{~kg} / \mathrm{m}^{3}$, and the maximum water-cement ratio is 0.5 . Besides, nuclear power construction water and related raw materials should also follow specified requirements. Moreover, the performance of the cured concrete needs to be tested ensuring that it meets the performance requirements of nuclear power containment [21].

The designed strength of NPCC in this study is C40. The raw materials requirements for this type of concrete include cement, water, coarse aggregate, fine aggregate, fly ash, and water reducing agent. Specifically, the cement adopted is $\mathrm{P}$. O 42.5 ordinary Portland cement; the coarse aggregate adopted is natural gravels with particle size ranging from $4 \mathrm{~mm}$ to $16 \mathrm{~mm}$; the fine aggregate adopted is river sands with the apparent density of $2645 \mathrm{~kg} / \mathrm{m}^{3}$ and fineness modulus of 2.6; the water reducing agent adopted is polycarboxylic acid-based superplasticizer (naphthalene sulfonated formaldehyde condensate water reducing agent, where the content of water reducing agent is $1.0 \% \sim 2.0 \%$ of the cement content, and the corresponding water reduction rate is $20 \% \sim 30 \%)$. The fly ash adopted was Classifly ash obtained from a power plant; its residual amount is $5.5 \%$ after filtering through a $0.045 \mathrm{~mm}$ square-hole sieve; its loss on ignition is $4.6 \%$; its calcium oxide content is $3.66 \%$; and its 28 -day activity index is $79.7 \%$. According to the "Specification for Mix Proportion Design of Ordinary Concrete" (JGJ55-2011) and the actual mix proportion of a nuclear power plant, the mix proportion of NPCC is determined as shown in Table 1.

2.2. Experiment Loading Scheme. This study mainly aimed to study the size effect on the compressive dynamic performance of NPCC. Two basic conditions, that is, the designed size of the concrete specimens and the loading strain rate, are considered in this study. To examine the size effect, 3 different cube sizes, $70 \mathrm{~mm} \times 70 \mathrm{~mm} \times 70 \mathrm{~mm}, 100 \mathrm{~mm} \times 100 \mathrm{~mm} \times 100 \mathrm{~mm}$, and $150 \mathrm{~mm} \times 150 \mathrm{~mm} \times 150 \mathrm{~mm}$, are designed.

The setting of loading strain rate for NPCC is mainly determined based on the seismic loading level. In literature [17], the defined range for static loading strain rate and seismic loading strain rate is $1.0 \times 10^{-6} / \mathrm{s} \sim 1.0 \times 10^{-5} / \mathrm{s}$ and $1.0 \times 10^{-3} / \mathrm{s} \sim 1.0 \times 10^{-2} / \mathrm{s}$, respectively. In order to facilitate the comparative analysis with the results of ordinary concrete in existing literature [22-26], 10 loading strain rates are selected in this study: $1.0 \times 10^{-5} / \mathrm{s}, 5.0 \times 10^{-5} / \mathrm{s}, 1.0 \times 10^{-4} / \mathrm{s}$, $5.0 \times 10^{-4} / \mathrm{s}, 1.0 \times 10^{-3} / \mathrm{s}, 2.0 \times 10^{-3} / \mathrm{s}, 5.0 \times 10^{-3} / \mathrm{s}, 1.0 \times 10^{-2} /$ $\mathrm{s}, 2.0 \times 10^{-2} / \mathrm{s}$, and $5.0 \times 10^{-2} / \mathrm{s}$, where the loading strain rate of $1.0 \times 10^{-5} / \mathrm{s}$ is defined as static loading strain rate, while the others are dynamic loading strain rates. The compressive strength characteristic value at the static loading strain rate is taken as a benchmark. In view of the randomness and discreteness of concrete, 3 test specimens are prepared for each loading condition, and the mean value is used for analysis. 
TABLE 1: Mix proportion of NPCC $\left(\mathrm{kg} / \mathrm{m}^{3}\right)$.

\begin{tabular}{lccccc}
\hline Cement & Water & Coarse aggregate & Fine aggregate & Fly ash & Water reducing agent \\
\hline 486 & 205 & 1027 & 629 & 54 & 1.5 \\
\hline
\end{tabular}

A hydraulic servo equipped with an independent load sensor and displacement sensor as shown in Figure 1 is used to prepare for the test. In this study, the mixed loading method is adopted; that is, the load control method is first adopted, and the loading rate is $0.3 \mathrm{MPa} / \mathrm{s}$. After the load reaches $20 \mathrm{kN}$, the load was released. This process is applied three times to eliminate the gap between the test specimen and the loading surface of the equipment. Then, the formal loading process is performed, and the displacement-controlled loading method is used under the loading strain rates as the above. Before loading, the mechanical grease is applied onto the concrete loading surface to reduce the friction, in order to control the impact of the friction between the concrete loading surfaces of and the equipment loading side on the test results.

\section{Analysis of Test Results}

3.1. Failure Mode. The failure modes of the specimens under different loading conditions are obtained and analyzed. According to the failure mode, the mechanical characteristics of concrete can be examined from a macroscopic perspective. In view of the space constraint, specimens with a size $70 \mathrm{~mm} \times 70 \mathrm{~mm} \times 70 \mathrm{~mm}$ at three loading strain rates $\left(1.0 \times 10^{-5} / \mathrm{s}, 1.0 \times 10^{-3} / \mathrm{s}\right.$, and $\left.1.0 \times 10^{-2} / \mathrm{s}\right)$ are selected to study the failure modes effected by dynamic strain rate. The failure specimens under different loading strain rates are presented in Figure 2.

According to Figure 2, it can be seen that the concrete cracks are uniformly distributed around the test specimen at the static loading strain rate of $1.0 \times 10^{-5} / \mathrm{s}$. The failure mainly occurs at the cement cementitious layer between the mortar and the coarse aggregate. The specimen still keeps a relatively good integrity after failure. With the increase of the loading strain rate, the concrete cannot hold together and gradually forms oblique cracks. There are usually $2 \sim 3$ main penetrating cracks, which tend to penetrate up and down and are accompanied by the fracture failure of coarse aggregate. The integrity of the specimen after destruction under dynamic loading conditions is much worse. The possible mechanism for such phenomenon is that when the loading strain rate is relatively low, the internal cracks inside the specimen can fully develop and expand. Therefore, the specimen is subjected to a relatively uniform stress; as the loading strain rate increases, the compressive stress on the specimen cannot be uniformly formed in a short time, so that the internal cracks cannot develop and expand uniformly, which eventually leads to the dynamic failure mode as shown in Figure 2. From the macroscale view, the critical strain rate is about $2.0 \times 10^{-3} / \mathrm{s}$. When the strain rate is higher than this, some coarse aggregates failure occurs in the concrete. When the strain rate is lower than this, the failure mode is the failure of the cement

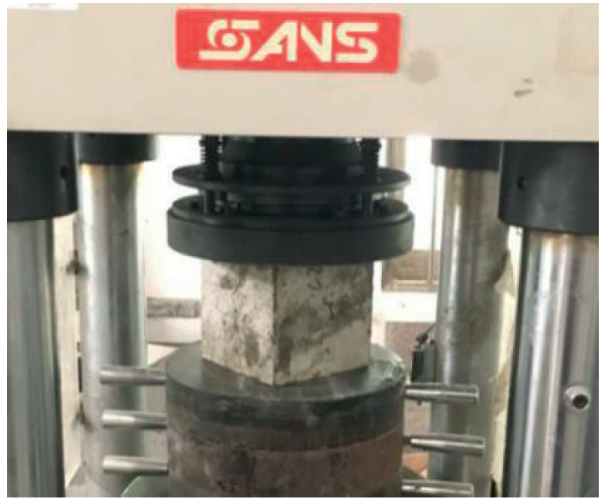

Figure 1: The hydraulic servo.

cementitious layer between the mortar and coarse aggregates. The reason for the analysis is that, under high strain rate loading, the loading time of concrete specimen is too short, and the uniform stress distribution cannot be formed, and the cracks are not fully developed, which eventually cause the destruction of some coarse aggregates for the high strain rate concrete specimen.

From the above analysis, it can be seen that the concrete failure under static loading is mainly the bonding interface failure, while the failure under dynamic loading is mainly the penetrating failure accompanied by fractures of some coarse aggregate. The fracture failure of coarse aggregate requires a much larger load than the bonding interface failure. As a result, the concrete compressive strength is gradually increased as the loading strain rate increased. Scanning Electron Microscopy (SEM) is applied to analyze the experimental phenomenon from a microscopic perspective. In view of the space constraint of this paper, the $100 \mathrm{~mm} \times 100 \mathrm{~mm} \times 100 \mathrm{~mm}$ cube is selected as a sample to analyze the bonding interface between the cement mortar layer and coarse aggregate under the loading strain rates of $1.0 \times 10^{-5}$ and $5.0 \times 10^{-2}$, as shown in Figure 3 .

The concrete coarse aggregate and cement mortar can be clearly differentiated. The coarse aggregate is a dense component, while the cement mortar contains more pores, as shown in Figure 3. It can be seen that when the loading strain rate is relatively low, the concrete failure mainly occurs at the interface between the mortar and coarse aggregate, and the cement mortar contains many cracks. As the loading strain rate increases, some micro cracks appear in the coarse aggregate compared with the low loading strain rate condition, and the cracking failure in both the coarse aggregate and cement mortar layer is obvious. This is consistent with the mechanism for the loading strain rate effect on the compressive strength as discussed above. The small black hole in Figure 3(a) is the initial defect of the microvoid, which is formed by the evaporation of the 


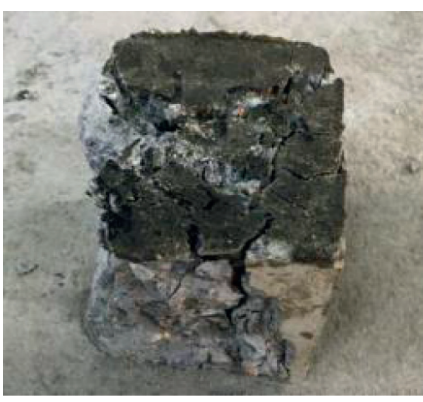

(a)

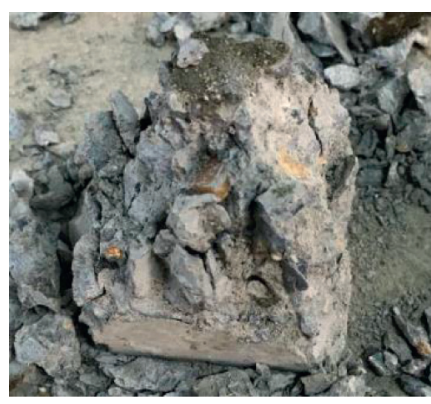

(b)

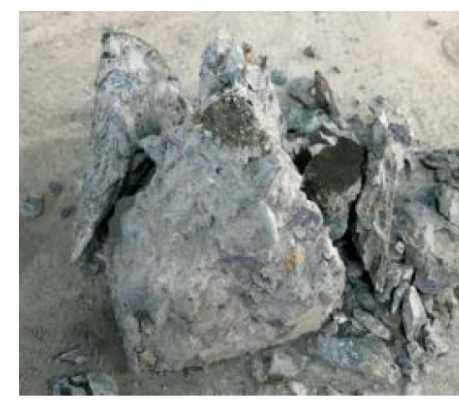

(c)

FIGURE 2: The failure mode under the effect of loading strain rate. (a) $1.0 \times 10^{-5} / \mathrm{s}$. (b) $1.0 \times 10^{-3} / \mathrm{s}$. (c) $1.0 \times 10^{-2} / \mathrm{s}$.

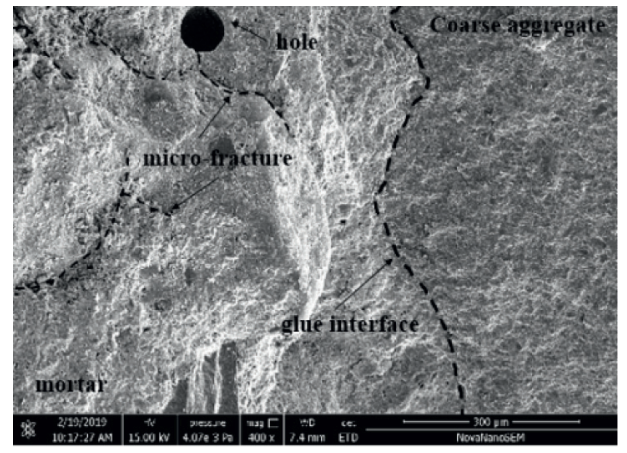

(a)

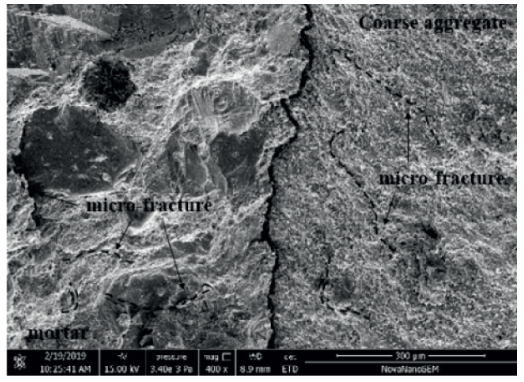

(b)

FIgURE 3: The SEM images of the failure NPCC at two different stain rates. (a) $1.0 \times 10^{-5}$. (b) $5.0 \times 10^{-2}$.

moisture of the concrete mix mortar during the concrete curing process. This type of defect and the interface between cement mortar and coarse aggregate are the major factor causing the nonlinearity and randomness of concrete; to a certain extent, it shows the compactness of concrete. Compared with the ordinary cement concrete, as shown in Figure 4, from the SEM images, it can be seen that NPCC contains lower voids and the cement mortar is relatively dense, but the ordinary concrete has higher voids and the dense of cement mortar is relatively low. Thus, the density of NPCC is relatively higher.

To examine the size effect, the failure modes of different size specimens under the loading strain rate of $1.0 \times 10^{-5} / \mathrm{s}$ and $1.0 \times 10^{-3} / \mathrm{s}$ are selected and analyzed, and the failure specimens are shown in Figures 5 and 6.

Figures 5 and 6 show the failure mode of the concrete specimen with different sizes. With the increase of the vertical load, tensile strain is formed in the direction perpendicular to the vertical plane due to Poisson's ratio effect, which increases gradually with the increase of the vertical load. The failure mechanism of concrete under uniaxial compression reflects that the effect of Poisson's ratio is not related to the loading strain rate and specimen size. When the tensile strain exceeds the ultimate tensile strain of NPCC, the test specimen will be destroyed. As the cube length increases, the integrity of the specimen is getting improved, but the crack development pattern

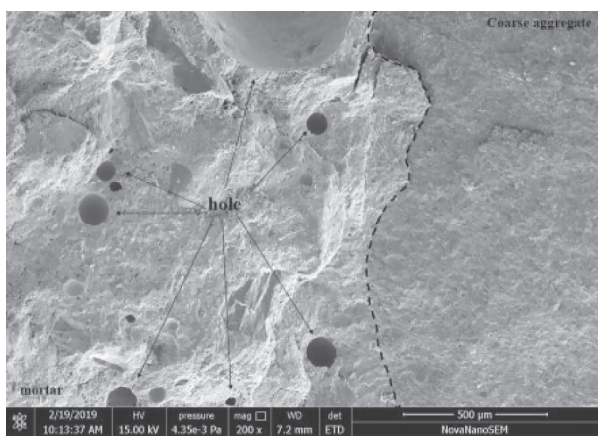

FIgURE 4: The SEM images of the failure ordinary concrete at $10^{-5} / \mathrm{s}$.

remains basically the same. Specifically, the micro cracks of the $150 \mathrm{~mm} \times 150 \mathrm{~mm} \times 150 \mathrm{~mm}$ cube show a similar failure mode to the other two sizes. The reason is that, with the increase of the side length of the concrete cube, the integrity of specimen is relatively high after the concrete is damaged by compression. The main reason is that, due to the size effect, as the side length increases, the compressive peak stress of the concrete is decreased; that is, the stress on the specimen of each concrete unit is relatively small after the large-sized specimen is compressed, and the small-sized specimen is the opposite. Ultimately, the 


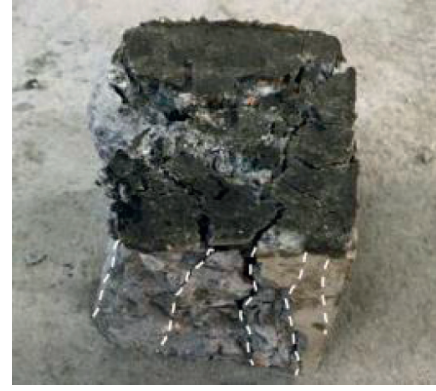

(a)

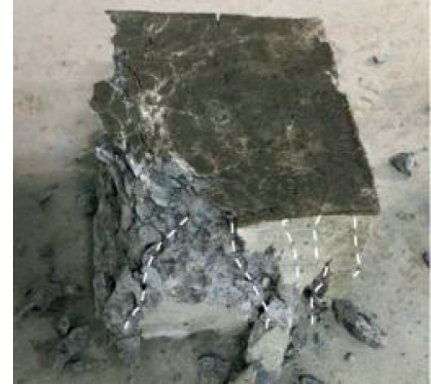

(b)

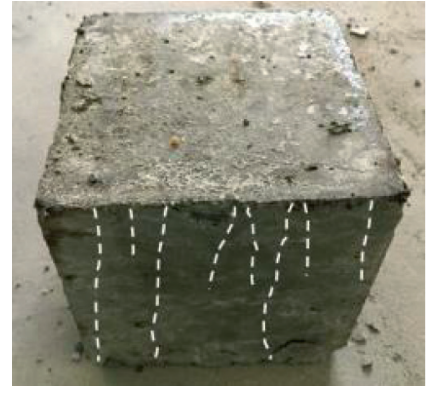

(c)

Figure 5: The failure mode under size effect $\left(1.0 \times 10^{-5} / \mathrm{s}\right)$. (a) $L=70 \mathrm{~mm}$. (b) $L=100 \mathrm{~mm}$. (c) $L=150 \mathrm{~mm}$.

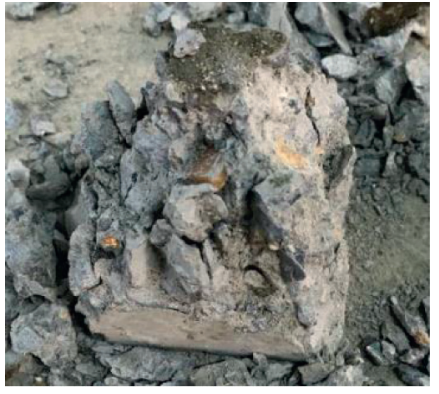

(a)

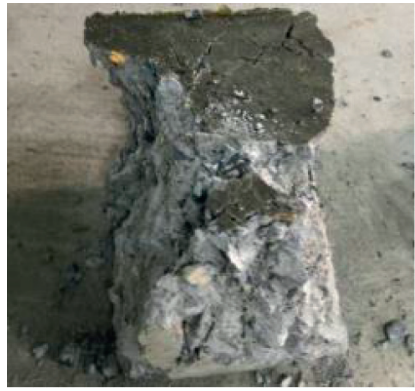

(b)

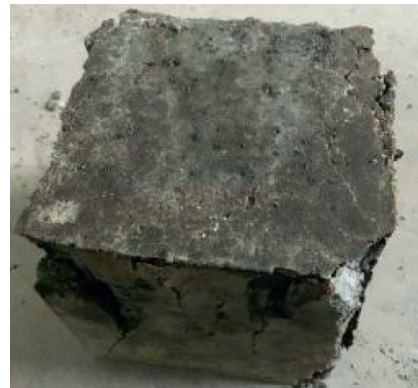

(c)

Figure 6: The failure mode under size effect $\left(1.0 \times 10^{-3} / \mathrm{s}\right)$. (a) $L=70 \mathrm{~mm}$. (b) $L=100 \mathrm{~mm}$. (c) $L=150 \mathrm{~mm}$.

integrity of larger specimens after compression damage is relatively high.

Concrete is featured with a quasi-brittleness characteristic. Its failure mode under a loading condition develops and expands from internal micro cracks. As the load increases, the internal cracks of concrete gradually merge with each other to form larger cracks. As a result, the specimens are gradually destroyed. Before the failure of specimen, the development of large cracks is mainly caused by the release of elastic energy, which changes along with the specimen size, and finally the specimen size will impose an obvious effect on the mechanical performance of concrete.

3.2. Compressive Strength. According to the experiment overview described above, a hydraulic servo is used to perform uniaxial compression test on 3 different sizes (size 1: $70 \mathrm{~mm} \times 70 \mathrm{~mm} \times 70 \mathrm{~mm}$; size 2: $100 \mathrm{~mm} \times 100 \mathrm{~mm} \times 100 \mathrm{~mm}$; size 3: $150 \mathrm{~mm} \times 150 \mathrm{~mm} \times 150 \mathrm{~mm}$ ) of concrete specimens under 10 different loading strain rates. The results of compressive strength characteristic values are shown in Table 2.

3.2.1. Dynamic Performance Effect. For quantitative research regarding concrete compressive dynamic characteristics, the dynamic improvement coefficient $\alpha_{\mathrm{DIF}}$ is commonly used for quantitative analysis in order to examine the effect of loading strain rate on the compressive strength characteristic value of concrete [22]. $\alpha_{\text {DIF }}$ can be calculated using the following equation:
TABle 2: The compressive strength characteristic values under different loading conditions (MPa).

\begin{tabular}{lccc}
\hline Strain rate & Size 1 & Size 2 & Size 3 \\
\hline $1.0 \times 10^{-5}$ & 35.92 & 33.52 & 31.14 \\
$5.0 \times 10^{-5}$ & 37.22 & 35.07 & 32.14 \\
$1.0 \times 10^{-4}$ & 39.33 & 35.49 & 33.03 \\
$5.0 \times 10^{-4}$ & 41.84 & 37.65 & 33.93 \\
$1.0 \times 10^{-3}$ & 43.36 & 38.79 & 35.16 \\
$2.0 \times 10^{-3}$ & 43.50 & 39.42 & 35.63 \\
$5.0 \times 10^{-3}$ & 45.53 & 40.23 & 36.18 \\
$1.0 \times 10^{-2}$ & 47.09 & 40.70 & 36.24 \\
$2.0 \times 10^{-2}$ & 48.42 & 42.14 & 36.47 \\
$5.0 \times 10^{-2}$ & 50.11 & 43.69 & 37.75 \\
\hline
\end{tabular}

$$
a_{\mathrm{DIF}}=\frac{\sigma_{d}}{\sigma_{\mathrm{s}}}
$$

where $\alpha_{\text {DIF }}$ represents the compressive strength dynamic improvement coefficient of the concrete; $\sigma_{\mathrm{s}}$ represents the compressive strength of the concrete under static loading strain rate (the strain rate is equal to $1.0 \times 10^{-5} / \mathrm{s}$ ) in the unit of $\mathrm{MPa} ; \sigma_{\mathrm{d}}$ represents the compressive strength of the concrete under dynamic loading strain rate (greater than $1.0 \times 10^{-5} / \mathrm{s}$ ) in the unit of $\mathrm{MPa}$.

From Table 2, the relationship between the compressive strength characteristic value and the loading strain rate for 3 cube sizes is obtained, as shown in Figure 7. It can be seen that the compressive strength of the concrete is increased significantly with the increase of the loading strain rate. For the cube size of $70 \mathrm{~mm} \times 70 \mathrm{~mm} \times 70 \mathrm{~mm}$, the compressive 


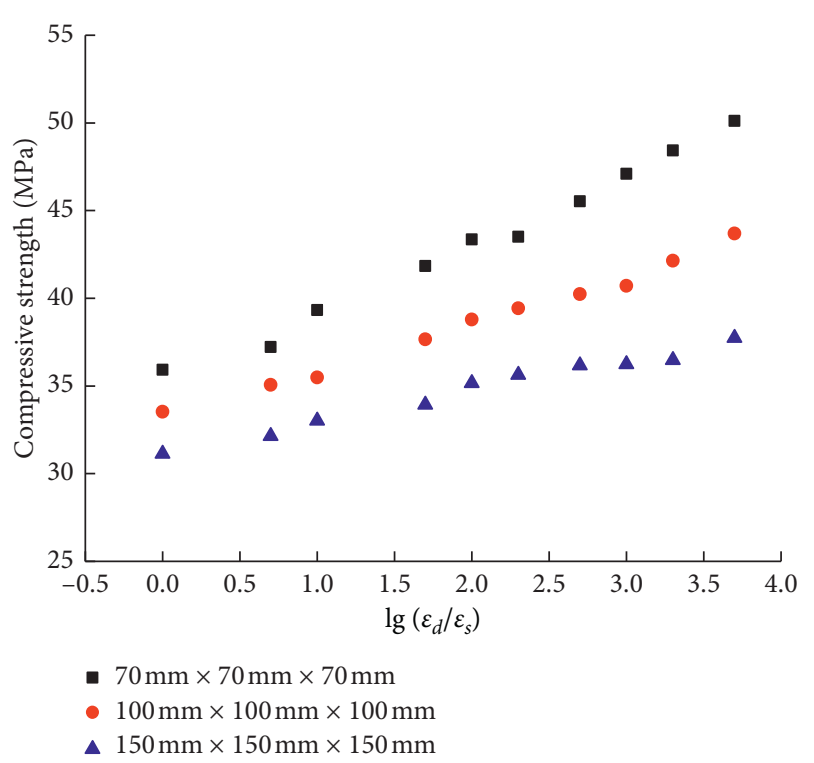

Figure 7: Relationship between loading strain rate and compressive strength.

strength is increased from $35.92 \mathrm{MPa}$ to $50.11 \mathrm{MPa}$, with an improvement of $39.50 \%$. For the cube size of $100 \mathrm{~mm} \times 100 \mathrm{~mm} \times 100 \mathrm{~mm}$, the compressive strength is increased from $33.52 \mathrm{MPa}$ to $43.69 \mathrm{MPa}$, with an improvement of $30.34 \%$. For the cube size of $150 \mathrm{~mm} \times 150 \mathrm{~mm} \times 150 \mathrm{~mm}$, the compressive strength increases from $31.14 \mathrm{MPa}$ to $37.75 \mathrm{MPa}$, with an improvement of $21.23 \%$. Specifically, for the cube size of $150 \mathrm{~mm} \times 150 \mathrm{~mm} \times 150 \mathrm{~mm}$, the increase in compressive strength is the lowest. Zeng and Li [23] investigated the compressive strength of a cylinder concrete size of $\Phi 100 \mathrm{~mm} \times 200 \mathrm{~mm}$ under the effect of a loading strain rate ranging from $1.0 \times 10^{-5} / \mathrm{s}$ to $3.5 \times 10^{-2} / \mathrm{s}$. It was found that the compressive strength was increased by around $25 \%$. Shi et al. [24] investigated the compressive strength of the cubic concrete size of $150 \mathrm{~mm} \times 150 \mathrm{~mm} \times 150 \mathrm{~mm}$ under the effect of a loading strain rate ranging from $2.0 \times 10^{-5} / \mathrm{s}$ to $2 \times 10^{-2} / \mathrm{s}$ and reported that the compressive strength increased by $33.53 \%$. For the cubic concrete size of $100 \mathrm{~mm} \times 100 \mathrm{~mm} \times 100 \mathrm{~mm}$, under the effect of a loading strain rate ranging from $1.0 \times 10^{-5} / \mathrm{s}$ to $5 \times 10^{-2} / \mathrm{s}$, the compressive strength was increased by $34.36 \%$ [25]. When strain rate increases to $200 / \mathrm{s}$, the influence of strain rate on dynamic strength will be different, as shown on the literature [1]. Compared with the test results of ordinary concrete, the increase of uniaxial compressive strength of NPCC with the increase of loading strain rate exhibits a consistent pattern. This conclusion is in line with the concepts of concrete damage mechanics, which suggests that a high loading strain rate can lead to the hysteresis effect in the evolution of concrete damage. As a result, the compressive strength becomes higher than that under static loading; as the loading strain rate increases, the compressive strength is also gradually increased. Across different experimental studies, it is found that the increase of compressive strength differs to a certain extent with the increase of loading strain rate; this is due to the randomness and discreteness of the concrete material and the influence of the loading environment [26].

In order to quantitatively analyze the variation pattern of compressive strength under the effect of loading strain rate, equation (2) is used to describe the relationship between the compressive strength dynamic improvement coefficient and the loading strain rate:

$$
\alpha_{\mathrm{DIF}}=b+a \lg \left(\frac{\dot{\varepsilon}_{\mathrm{d}}}{\dot{\varepsilon}_{\mathrm{s}}}\right) .
$$

In literature [22], equation (2) was applied to perform mathematical regression analysis on the experimental data of compressive dynamic performance, and a linear relationship was found between the dynamic improvement coefficient of concrete and the logarithmic value of the strain rate after dimensionless processing. Specifically, coefficient $b$ is generally ranged $0.98 \sim 1.02$. Considering that coefficient $b$ is the dynamic improvement coefficient under the static loading condition, set coefficient $b=1$. Then, the relationship between $\alpha_{\text {DIF }}$ and the loading strain rate can be obtained as shown in the following equation:

$$
\alpha_{\mathrm{DIF}}=1+a \lg \left(\frac{\dot{\varepsilon}_{\mathrm{d}}}{\dot{\varepsilon}_{\mathrm{s}}}\right) .
$$

According to equation (3), mathematical regression is performed using the compressive dynamic performance data as shown in Table 2 for 3 cube-size concrete specimens. Then, the $\alpha_{\text {DIF }}$ relationship equations are obtained as shown in Figure 5 and equations (4)-(6).

For the size of $70 \mathrm{~mm} \times 70 \mathrm{~mm} \times 70 \mathrm{~mm}$,

$$
\alpha_{\mathrm{DIF}}=1+0.102 \lg \left(\frac{\dot{\varepsilon}_{\mathrm{d}}}{\dot{\varepsilon}_{\mathrm{s}}}\right) \text {. }
$$

For the size of $100 \mathrm{~mm} \times 100 \mathrm{~mm} \times 100 \mathrm{~mm}$,

$$
\alpha_{\mathrm{DIF}}=1+0.076 \lg \left(\frac{\dot{\varepsilon}_{\mathrm{d}}}{\dot{\varepsilon}_{\mathrm{s}}}\right) \text {. }
$$

For the size of $150 \mathrm{~mm} \times 150 \mathrm{~mm} \times 150 \mathrm{~mm}$,

$$
\alpha_{\mathrm{DIF}}=1+0.057 \lg \left(\frac{\dot{\varepsilon}_{\mathrm{d}}}{\dot{\varepsilon}_{\mathrm{s}}}\right) \text {. }
$$

According to Figure 8 and equations (4)-(6), there is a linear relationship between the compressive strength dynamic improvement coefficient and the logarithmic value of the strain rate after dimensionless processing for the 3 cubesize concrete specimens and the proposed equations exhibit a good applicability. Based on the analysis of coefficient $a$, that is, the variation coefficient of different sizes under the effect of loading strain rate, cube size of $150 \mathrm{~mm} \times 150 \mathrm{~mm} \times 150 \mathrm{~mm}$ has the smallest $a$, while cube size of $70 \mathrm{~mm} \times 70 \mathrm{~mm} \times 70 \mathrm{~mm}$ has the largest $a$, indicating that the smaller the cube length, the greater the increase of compressive strength under the effect of dynamic performance.

With the increase of the cube length, the increase of the concrete compressive strength characteristic value is gradually reduced under the effect of the loading strain rate, and 


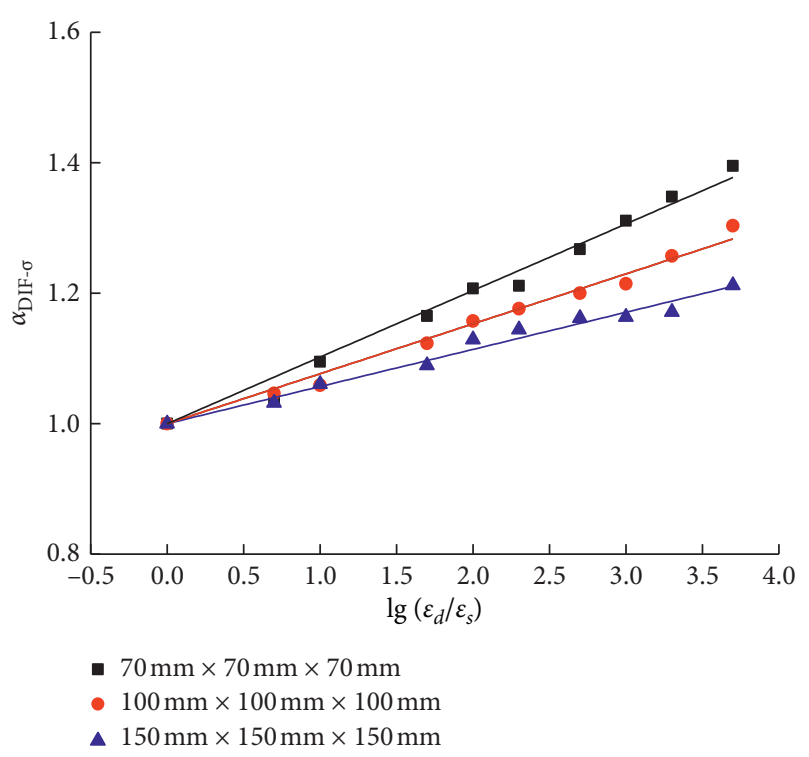

FIgURE 8: Relationship between loading strain rate and dynamic improvement coefficient.

the influence of concrete on dynamic performance is relatively low. From the failure mode perspective, the integrity of the $150 \mathrm{~mm}$ specimen remains good after destruction. At the same time, as the loading strain rate increases, the failure mode of the $150 \mathrm{~mm}$ specimen only develops to the obliquecrack mode under a higher strain rate in comparison with the other two specimen sizes, and there is a fracture-damage failure in the coarse aggregate. It indicates that a larger-sized concrete specimen is relatively weaker affected by dynamic performance of concrete. Moreover, for a larger-sized concrete specimen, the increase of the compressive strength characteristic value is relatively small under the effect of loading strain rate. This was probably because the development of cracks in a larger specimen requires a higher deformation value, and it has a stronger ability to maintain uniform stress distribution, which ultimately leads to the fact that the larger the cube side length, the lower the dynamic rate effect.

3.2.2. Size Effect. According to the compressive strength characteristic values under different loading conditions as shown in Table 2, the experimental data of compressive strength affected by size effect are analyzed under 10 loading strain rates, in order to examine the relationship between the compressive strength and the cube length under different loading strain rates, as shown in Figure 9.

According to Figure 9, under the same loading strain rate, the compressive strength of the concrete specimen is gradually decreased with the increase of the cube length. When the loading strain rate is $1.0 \times 10^{-5} / \mathrm{s}$, the variation amplitude of the compressive strength affected by the size effect is $2.39 \mathrm{MPa}$. When the loading strain rate is $5.0 \times 10^{-2} / \mathrm{s}$, the variation amplitude of the compressive strength affected by size effect is $12.36 \mathrm{MPa}$. Based on the overall trend analysis, as the loading strain rate increases, the variation amplitude of the compressive strength

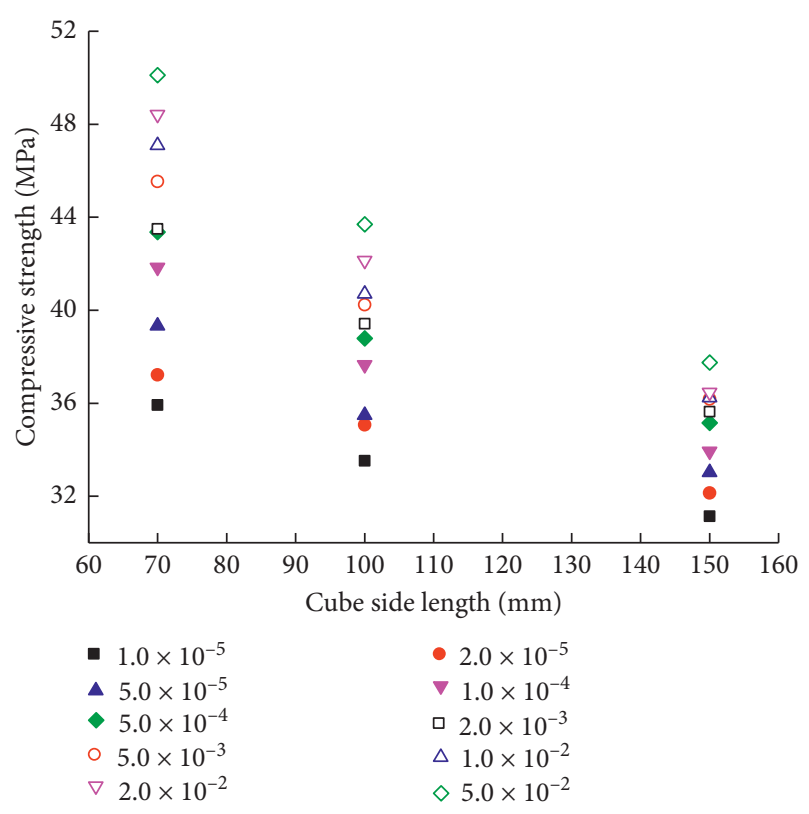

FIgURE 9: Relationship between cube length and compressive strength.

affected by size effect is gradually increased. As the cube length increases, the effect of the loading strain rate on the compressive strength characteristic value gradually decreases.

In order to further explore the influence of size effect, according to the compressive strength characteristic values under different loading conditions, the variation amplitude of the concrete compressive strength was obtained, under the same loading strain rate affected by size effect. The influence of the loading strain rate and the size effect on the variation amplitude of the concrete compressive strength is shown in Figure 10.

Based on the qualitative analysis on the variation amplitude of the concrete compressive strength and the loading strain rate, equation (7) is proposed, which describes the variation amplitude of the concrete compressive strength under the loading strain rate and size effect:

$$
\begin{aligned}
\frac{\left[\left(\sigma_{70}-\sigma_{100}\right)+\left(\sigma_{100}-\sigma_{150}\right)\right]}{2} & =2.047 \\
& +1.057 \lg \left(\frac{\dot{\varepsilon}_{\mathrm{d}}}{\dot{\varepsilon}_{\mathrm{s}}}\right), \quad R^{2}=0.95144 .
\end{aligned}
$$

According to Figure 10 and equation (7), as the loading strain rate increased, the variation amplitude of the compressive strength is increased gradually due to the size effect and maintains a linear relationship with the logarithmic value of the loading strain rate after dimensionless processing. In order to further explore the variation of the compressive strength under different loading strain rates affected by size effect, the compressive strength of cubic size of $70 \mathrm{~mm} \times 70 \mathrm{~mm} \times 70 \mathrm{~mm}\left(\sigma_{70}\right)$ is considered as the benchmark, while $\sigma_{100}$ and $\sigma_{150}$ are 


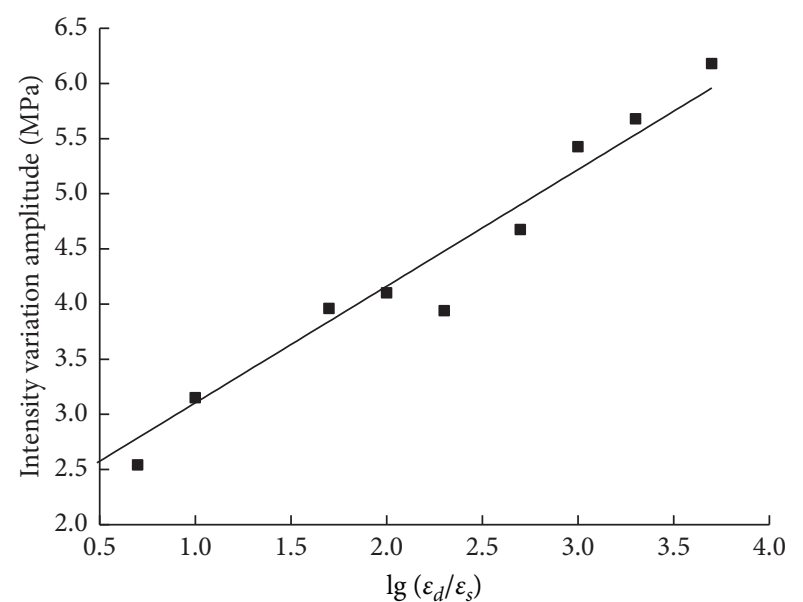

FIGURE 10: Influence of loading strain rate and size effect on the variation amplitude of the concrete compressive strength.

taken as the analysis value $\sigma$. Then, the relationship between the loading strain rate and the variation coefficient of compressive strength $\left(\sigma / \sigma_{70}\right)$ is obtained, as shown in Figure 11.

Figure 11 shows the relationship between the concrete cube length and the variation coefficient of compressive strength under different loading strain rates. Under the same loading strain rate, as the cube length increases, the concrete compressive strength is gradually decreased. When the loading strain rate ranged from $1.0 \times 10^{-5} / \mathrm{s}$ to $1.0 \times 10^{-4} / \mathrm{s}$, the compressive strength of $150 \mathrm{~mm}$ cube is reduced by $13.31 \% \sim 18.91 \%$ compared with that of $70 \mathrm{~mm}$ cube. When the loading strain rate ranged from $2.0 \times 10^{-3} / \mathrm{s}$ to $5.0 \times 10^{-2} / \mathrm{s}$, the compressive strength of $150 \mathrm{~mm}$ cube is reduced by $18.90 \% \sim 24.67 \%$. The overall trend shows that as the loading strain rate increases, the variation amplitude of the concrete compressive strength affected by size effect gets larger.

As the loading strain rate increases, the size effect on the concrete compressive strength is gradually increased. The underlying mechanism is that, with the increase of the loading strain rate, the concrete compressive strength will be significantly increased. The size effect of concrete is closely correlated with its compressive strength. The existing research regarding the size effect on the compressive strength of concrete with different strengths shows that, alongside the increase of concrete strength, the variation amplitude of the strength characteristic value under size effect is significantly increased. High-strength concrete is subject to a more significant size effect [7]. Therefore, the size effect on the concrete compressive strength is becoming increasingly obvious with the increase of the loading strain rate. Some different conclusions are obtained compared with other researches in literature [10]. The main reasons for the analysis are that the coupling effect of strain rate and size effect and the randomness and discreteness of the concrete itself make the mechanical properties of concrete more complicated. The differences of the concrete sizes may lead to the different research results. As mentioned in literature [10], the "material effect" and "structural effect" may be affected to a certain extent by the values of different size ranges, and this aspect needs to be verified through further experiments. According to the basic law of the strain rate effect, as the loading strain rate increases, the compressive strength of concrete will increase significantly; according to the basic law of size effect, the concrete with high measured strength will have a significant increase in the size effect; thus, the increase of the strain rate has a certain promotion effect on the concrete size effect, which is similar to the conclusion of the literature experimental research [27, 28]. Literature [10] is a numerical simulation study on the dimensional effect of compressive dynamic performance of ordinary concrete. This paper conducts experimental research on the compressive dynamic performance of NPCC. In the numerical simulation analysis, certain factors will be simplified and considered to a certain extent. At the same time, the variation of the mechanical properties of concrete with different characteristics affected by the coupling effect of size effect and strain rate effect may also have some influence. Based on the above four possible reasons, further experimental research and theoretical analysis are needed to analyze its mechanism.

3.2.3. Combined Effect of Both Size Effect and Dynamic Performance. In the context of size effect research with respect to the concrete compressive strength, quantitative analysis is usually carried out from two perspectives, namely, the size effect and the size effect law [9]. Bazant [29] proposed the size effect formula for the compressive strength of concrete from the perspective of the size effect law. Based on this formula, this paper performs the corresponding dimensionless processing based on the expression method in literature [9] and obtains the expression form as shown in the following equation:

$$
\frac{\sigma}{\sigma_{70}}=c\left(1+\frac{d}{D}\right),
$$

where $\sigma$ is the nominal compressive strength; $D$ is the specimen length; $d$ is the characteristic dimension of the concrete specimen; and $c$ is the parameter to be determined.

According to Figure 12 and the data in Table 3, the size effect law equation is a satisfactorily quantitative expression for the size effect of the concrete compression characteristic value under different loading strain rates. Based on the analysis of Table 3, the influence of the loading strain rate on the relevant parameter value of the size effect law equation is examined, and the relationship between the loading strain rate and the size effect law parameters $c$ and $d$ is analyzed, as shown in Figure 13.

According to the relationship between the size effect law parameters and the loading strain rate as shown in Figure 13, $c$ and $d$ both have a linear relationship with the dimensionless logarithmic value of the loading strain rate. Therefore, the linear variation equation is used to 


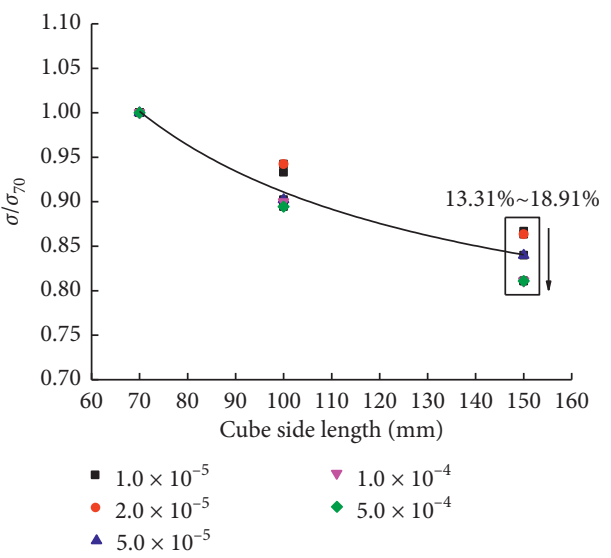

(a)

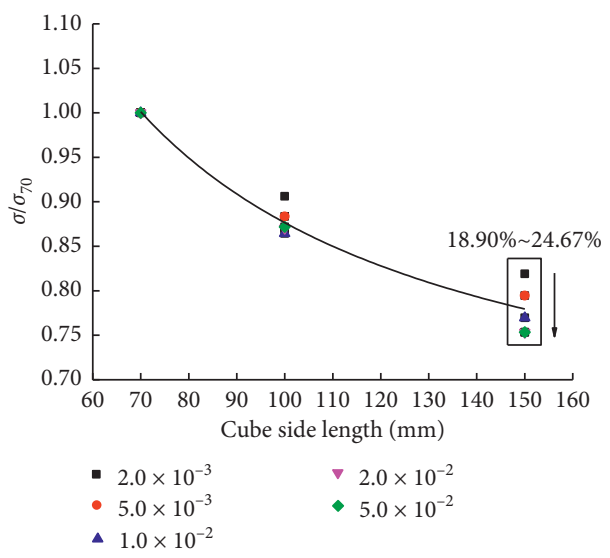

(b)

FiguRE 11: The relationship between the concrete cube length and the variation coefficient of compressive strength.

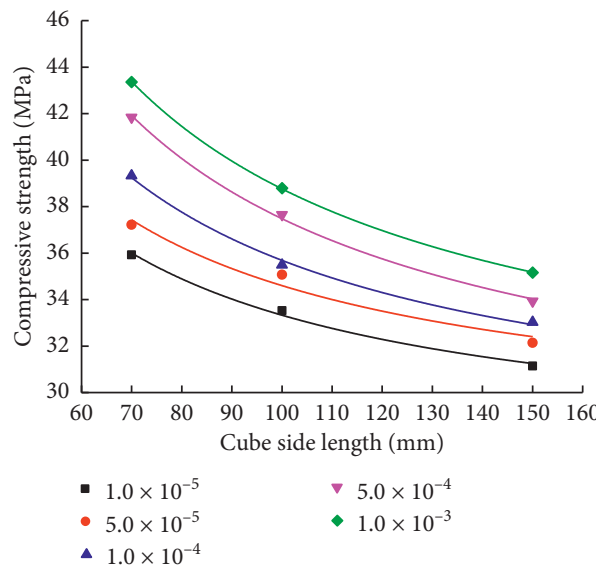

(a)

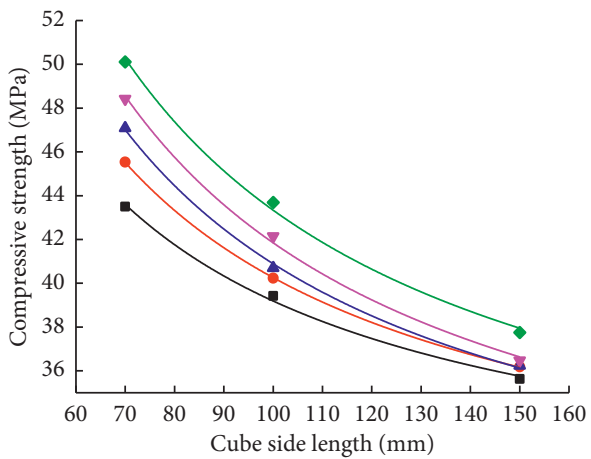

$\begin{array}{ll}\text { - } 2.0 \times 10^{-3} & \text { จ } 2.0 \times 10^{-2} \\ \text { - } 5.0 \times 10^{-3} & \\ \text { - } 1.0 \times 10^{-2} & \end{array}$

(b)

Figure 12: Relationship between concrete cube length and compressive strength. (a) $1.0 \times 10^{-5} / \mathrm{s} \sim 1.0 \times 10^{-3}$. (b) $2.0 \times 10^{-3} \sim 5.0 \times 10^{-2}$.

TABLE 3: Size effect law parameters of NPCC under different loading strain rates.

\begin{tabular}{lccc}
\hline Strain rate & $C$ & $d$ & $R^{2}$ \\
\hline $1.0 \times 10^{-5}$ & 0.754 & 23.05 & 0.9903 \\
$5.0 \times 10^{-5}$ & 0.753 & 23.53 & 0.9489 \\
$1.0 \times 10^{-4}$ & 0.696 & 30.31 & 0.9942 \\
$5.0 \times 10^{-4}$ & 0.648 & 38.17 & 0.9972 \\
$1.0 \times 10^{-3}$ & 0.646 & 38.42 & 0.9999 \\
$2.0 \times 10^{-3}$ & 0.664 & 35.61 & 0.9949 \\
$5.0 \times 10^{-3}$ & 0.615 & 43.87 & 0.9999 \\
$1.0 \times 10^{-2}$ & 0.565 & 53.62 & 0.9982 \\
$2.0 \times 10^{-2}$ & 0.541 & 59.66 & 0.9964 \\
$5.0 \times 10^{-2}$ & 0.542 & 59.49 & 0.9951 \\
\hline
\end{tabular}

perform mathematical fitting analysis, explaining the relationship between the size effect law parameters $c$ and $d$ and the loading strain rate, as shown in the following equations:

$$
\begin{aligned}
& c=0.771-0.06305 \lg \left(\frac{\dot{\varepsilon}_{\mathrm{d}}}{\dot{\varepsilon}_{\mathrm{s}}}\right), \quad R^{2}=0.92261, \\
& d=18.6321+10.7564 \lg \left(\frac{\dot{\varepsilon}_{\mathrm{d}}}{\dot{\varepsilon}_{\mathrm{s}}}\right), \quad R^{2}=0.90017 .
\end{aligned}
$$

In order to consider the coupling of size effect and loading strain rate on the concrete compressive strength, equations (9) and (10) are substituted into equation (8) to obtain the equation describing the coupling of size effect and dynamic performance on the compressive strength of NPCC, as follows:

$$
\begin{aligned}
\sigma= & \sigma_{70} \times\left[0.771-0.06305 \lg \left(\frac{\dot{\varepsilon}_{\mathrm{d}}}{\dot{\varepsilon}_{\mathrm{s}}}\right)\right] \\
& \times\left[1+\frac{18.6321+10.7564 \lg \left(\dot{\varepsilon}_{\mathrm{d}} / \dot{\varepsilon}_{\mathrm{s}}\right)}{D}\right] .
\end{aligned}
$$




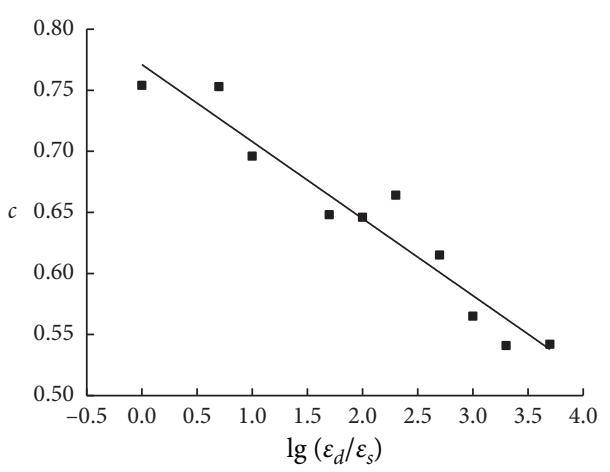

(a)

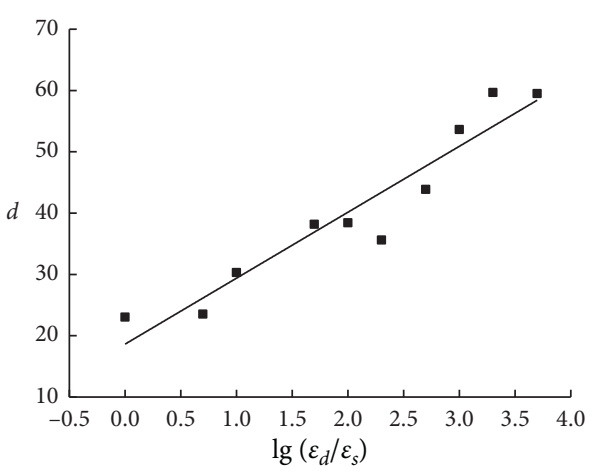

(b)

FIGURE 13: Relationship between size effect law parameters and loading strain rate.

According to the analysis of the strength change law under different sizes of concrete, as the size of the concrete specimen increases, the strength of the concrete continues to decrease. When the size of the concrete specimen decreases to a certain degree, the strength change of the concrete gradually stabilizes. The concrete strength that has stabilized at this time is the critical strength, and the corresponding size is the critical size. According to the critical strength value, the damage criterion of the concrete constitutive relationship is modified, thereby further modifying the concrete constitutive relationship and providing a theoretical basis for the finite element calculation of actual engineering concrete structures.

\section{Conclusions}

According to the compression experiments on NPCC specimens of 3 different cube sizes under 10 different loading strain rates, comparative analyses on the failure mode and compressive strength characteristic values of NPCC are conducted in order to understand the coupling of size effect and dynamic performance on NPCC. The main conclusions from the study are as follows:

(1) For the concrete cubes of the same size, as the loading strain rate increases, the failure mode gradually develops from uniformly distributed cracks under the static loading strain rate to oblique cracks under dynamic loading strain rates (oblique cracks as the main penetrating mode). Under the same loading strain rate, as the cube length increases, the integrity of the concrete after failure is relatively better.

(2) As the loading strain rate increases, the compressive strength of the same concrete cube is gradually increased. There is a linear relationship between the compressive strength dynamic coefficient and the dimensionless logarithmic value of the strain rate. At the same time, as the concrete cube length increases, the variation amplitude of the compressive strength under the effect of loading strain rate is gradually reduced.

(3) As the cube length increases, the concrete compressive strength is gradually reduced under the same loading strain rate. The variation amplitude of the compressive strength affected by the size effect is linearly correlated with the dimensionless logarithmic value of the strain rate. The size effect law equation can effectively describe the size effect on the compressive strength under different loading strain rates. With the increase of the loading strain rate, the size effect becomes increasingly significant.

(4) The equation for calculating the compressive strength of NPCC is proposed based on the size effect and dynamic performance. From the perspective of mechanism, the influence of the size effect and dynamic performance on the mechanical performance of concrete is analyzed. The research results show that the effect of concrete on the dynamic performance of actual concrete structures is lower than that of model tests.

\section{Data Availability}

The nature of the data is the experimental data of concrete of different sizes and strain rates under compression. The data used to support the findings of this study are available from the corresponding author upon request (e-mail: gxchen@ njtech.edu.cn).

\section{Conflicts of Interest}

There are no conflicts of interest.

\section{Acknowledgments}

This work was supported by the National Key R\&D Program of China (2018YFC1504301) and National Natural Science Foundation of China (51708273). The authors gratefully acknowledge the financial support.

\section{References}

[1] C. Mahrenholtz and R. Eligehausen, "Dynamic performance of concrete undercut anchors for nuclear power plants," Nuclear Engineering and Design, vol. 265, pp. 1091-1100, 2013.

[2] S. Cao, X. Hou, R. Qin et al., "Effect of specimen size on dynamic compressive properties of fiber-reinforced reactive 
powder concrete at high strain rates," Construction and Building Materials, vol. 194, pp. 71-82, 2019.

[3] L.-X. Nie, J.-Y. Xu, W.-B. Ren et al., "Effects of temperature and impact velocity on impact deformation and toughness of concrete," Journal of Vibration and Shock, vol. 34, no. 6, pp. 67-71, 2015.

[4] D. Yan and G. Lin, "Dynamic properties of concrete in direct tension," Cement and Concrete Research, vol. 36, no. 7, pp. 1371-1378, 2006.

[5] P. Cao, F. Jin, Z. Changjun, and D. Feng, "Investigation on statistical characteristics of asphalt concrete dynamic moduli with random aggregate distribution model," Construction and Building Materials, vol. 148, pp. 723-733, 2017.

[6] P. Cao, G. Li, J. Yu et al., "Research and application of random aggregate model in determining the fracture behavior of fourpoint bending beam with notch," Construction and Building Materials, vol. 202, pp. 276-289, 2019.

[7] A. M. Neville, "The influence of size of concrete test cubes on mean strength and standard deviation," Magazine of Concrete Research, vol. 8, pp. 41-45, 1956.

[8] G. M. Sabins and S. M. Mirza, "Size effects in model concretes," Journal of the Structural Division, ASCE, vol. 105, no. 6, pp. 141-152, 1979.

[9] J. Su and Z. Fang, "Scale effect on cubic compressive strength of ordinary concrete and high-strength concrete," Journal of Building Materials, vol. 16, no. 6, pp. 1078-1082, 2013.

[10] L. Jin, W. Yu, X. Du, S. Zhang, and D. Li, "Meso-scale modelling of the size effect on dynamic compressive failure of concrete under different strain rates," International Journal of Impact Engineering, vol. 125, pp. 1-12, 2019.

[11] L. Jin, W. Yu, X. Du, and W. Yang, "Mesoscopic numerical simulation of dynamic size effect on the splitting-tensile strength of concrete," Engineering Fracture Mechanics, vol. 209, pp. 317-332, 2019.

[12] L. Jin, S. Zhang, J. Han, D. Li, and X. Du, "Effect of crosssection size on flexural compressive failure of RC columns: monotonic and cyclic tests," Engineering Structures, vol. 186, pp. 456-470, 2019.

[13] M. Du, L. Jin, X. Du, D. Li et al., "Size effect tests of stocky reinforced concrete columns confined by stirrups," Structural Concrete, vol. 18, no. 3, pp. 454-465, 2017.

[14] X. Chen, S. Wu, and J. Zhou, "Large-beam tests on mechanical behavior of dam concrete under dynamic loading," Journal of Materials in Civil Engineering, vol. 27, no. 10, Article ID 06015001, 2015.

[15] J. Y. Wu, J. Li, and R. Faria, "An energy release rate-based plastic-damage model for concrete," International Journal of Solids and Structures, vol. 43, no. 3-4, pp. 583-612, 2006.

[16] J. Li and X. Ren, "Stochastic damage model for concrete based on energy equivalent strain," International Journal of Solids and Structures, vol. 46, no. 11-12, pp. 2407-2419, 2009.

[17] S. Shiming and S. Yupu, "Dynamic biaxial tensile-compressive strength and failure criterion of plain concrete," Construction and Building Materials, vol. 40, pp. 322-329, 2013.

[18] S. D. Adhikary, B. Li, and K. Fujikake, "Strength and behavior in shear of reinforced concrete deep beams under dynamic loading conditions," Nuclear Engineering and Design, vol. 259, pp. 14-28, 2013.

[19] O. Buyukozturk and J. J. Connor, "Nonlinear dynamic response of reinforced concrete under impulsive loading: research status and needs," Nuclear Engineering and Design, vol. 50, no. 1, pp. 83-92, 1978.
[20] S.-K. Lee, Y.-C. Song, and S.-H. Han, "Biaxial behavior of plain concrete of nuclear containment building," Nuclear Engineering and Design, vol. 227, no. 2, pp. 143-153, 2004.

[21] L. Wang, "The study mix design and performance of high strength high performance concrete for ERP nuclear containment," Progress Report on China Nuclear Science \& Technology, vol. 5, no. 10, pp. 263-269, 2017.

[22] D. Yan, K. Liu, L. Fan, and Z. Yang, "An experimental investigation of pre-loading effects on the dynamic behaviour of concrete," Magazine of Concrete Research, vol. 69, no. 11, pp. 586-594, 2017.

[23] S. Zeng and J. Li, "Experimental study on uniaxail compression behavior of concrete under dynamic loading," Journal of Tongji University (Natural Science), vol. 41, no. 1, pp. 7-10, 2013.

[24] L. Shi, Y. Song, and S. Lu, "Experimental study on uniaxial compression properties of large aggregate and wet-screened concrete at different strain rates," World Earthquake Engineering, vol. 32, no. 2, pp. 270-276, 2016.

[25] X. Sun and X. Xie, "Compression dynamic performance of ordinary concrete and lightweight aggregate concrete," Journal of Building Materials, vol. 21, no. 3, pp. 376-381, 2018.

[26] J. Li, J. Wu, and J. Chen, Stochastic Damage Mechanics of Concrete Structures, Science Press, Beijing, China, 2014.

[27] T. Krauthammer, M. M. Elfahal, J. Lim, T. Ohno, M. Beppu, and G. Markeset, "Size effect for high-strength concrete cylinders subjected to axial impact," International Journal of Impact Engineering, vol. 28, no. 9, pp. 1001-1016, 2003.

[28] M. M. Elfahal and T. Krauthammer, "Dynamic size effect in normal-and high-strength concrete cylinders," ACI Materials Journal, vol. 102, no. 2, pp. 77-85, 2005.

[29] Z. P. Bazant, "Size effect," International Journal of Solids and Structures, vol. 37, no. 1-2, pp. 69-80, 2000. 